\title{
Attitude of Medical Students towards Psychiatry: The case of Jimma University, Southwest Ethiopia
}

\author{
Hailemariam Hailesilassie ${ }^{1}$, Habtamu Kerebih ${ }^{1}$, Alemayehu Negash ${ }^{1}$, Eshetu \\ Girma $^{1}$, Mathias Siebeck ${ }^{3}$, Markos Tesfaye ${ }^{1}$
}

\author{
OPEN ACCESS \\ Citation: Hailemariam Hailesilassie., \\ Habtamu Kerebih., Alemayehu Negash., \\ Eshetu Girma., Mathias S., Markos \\ Tesfaye. Attitude of Medical Students \\ towards Psychiatry: J Health Sci \\ 2017;27(3):207. doi: \\ http://dx.doi.org/10.4314/ejhs.v27i3.2 \\ Received: November 25, 2016 \\ Accepted December 3, 2016 \\ Published: May 1, 2017 \\ Copyright: () 2017 Hailemariam, H., et \\ al. This is an open access article \\ distributed under the terms of the \\ Creative Commons Attribution License, \\ which permits unrestricted use, \\ distribution, and reproduction in any \\ medium, provided the original author and \\ source are credited. \\ Funding: Jimma University \\ Competing Interests: The authors \\ declare that this manuscript was approved \\ by all authors in its form and that no \\ competing interest exists. \\ Affiliation and Correspondence: \\ ${ }^{1}$ Department of Psychiatry, college \\ of Health science, Jimma University, \\ Ethiopia \\ ${ }^{2}$ Department of Preventive Medicine, \\ School of Public Health, Addis \\ Ababa University, Ethiopia \\ ${ }^{3}$ Departments of Surgery, Ludwig \\ Maximilian University, Munich, \\ Germany and Centers for \\ International Health, Ludwig \\ Maximilian University, Munich, \\ Germany \\ "Email: \\ hailemariamh2011@gmail.com, \\ hailerising@gmail.com
}

\section{ABSTRACT}

BACKGROUND: The inability to attract medical graduates to specialize in psychiatry has always been a serious challenge to psychiatry training programs. Therefore, the aim of this study was to assess the attitude of medical students towards psychiatry.

METHODS: A comparative cross-sectional survey was conducted among 122 fourth year medical students of Jimma University. The attitude of medical students towards psychiatry was measured by Attitude toward Psychiatry - 30 (ATP-30). The collected Data were analyzed by SPSS version-20 using independent samples t-test plus bivariate and multivariate logistic regression. The level of significance was determined at $95 \%$ confidence interval.

RESULTS: Medical students who did not take psychiatry clinical rotation had a higher ATP-30 mean score 55.52( \pm 15.2$)$ indicating positive attitude towards psychiatry than those who completed psychiatry clinical rotation (mean $=49.75 \pm 10.67$ ). Female medical students had significantly more positive attitude towards psychiatry than males (OR=9.23, 95\% CI: 2.32; 36.76). Medical students who did not take psychiatry clinical rotation had more positive attitude towards psychiatry than students who completed the psychiatry clinical rotation $(\mathrm{OR}=7.58,95 \%$ CI: $2.02 ; 28.37)$. Subjective experience of mental illness and reported family history of mental illness significantly predicted positive attitude toward psychiatry.

CONCLUSION: The findings suggest that doing psychiatry rotation might have affected the attitude of medical students towards psychiatry. Future research should assess the experiential factors during psychiatry training of medical students that affect their attitudes. Also, future research needs to evaluate the attitudes of fourth year medical students before and after their psychiatry clinical rotation.

KEYWORDS: Attitude, psychiatry, medical students, medical training 


\section{INTRODUCTION}

Mental, neurological and substance use disorders accounted for $14 \%$ of the global burden of diseases (GBDs) (1). Mental disorders are not only the highly prevalent medical conditions but also they are highly disabling ones. Based on the measure of years lived with disability and by premature death in disability-adjusted life years (DALYs), mental, neurological and substance used disorders are the leading causes of disability worldwide accounting for more than $33 \%$ of healthy life years lost from disability (YLDs) in low and middle income countries(1,2). Globally, around 450 million people suffer from mental disorders (3). However, many of these individuals with psychiatric disorders in low and middle income countries did not get treatment (4) due to a considerable shortage of psychiatrists, who are expected to play the leading role in mental health treatment $(5,6)$. Specifically, in sub-Saharan Africa countries, there is less than one psychiatrist for one million people (7). In Ethiopia, there is a significant shortage of psychiatrists in the mental health services with reports indicating 0.02 psychiatrists per 100,000 people (8). And, there is a very low stream of medical students joining psychiatry specialty. Research findings across the globe documented contradicting results. On the one hand, some reports from Middle East and western countries showed that medical students became more positive towards psychiatry (9-18). Studies done in west and east African countries also reported similar findings that the attitude of medical students towards psychiatry increased following psychiatry clinical rotation $(19,20)$.

A study done in the UK revealed that both male and female medical students showed no difference in their attitude towards psychiatry (12). However, in a study done in Pakistan, higher proportion of female students had more positive attitude as compared to their male counter parts (21). On the other hand, some studies reported negative attitude towards psychiatry among medical students after psychiatry clinical rotation $(22,23)$. Other studies, done among US and Israeli origin medical students, reported no difference in attitude towards psychiatry between the start and endpoint of psychiatry rotation (24-26).

In Ethiopia, there is no data on the attitude of medical students towards psychiatry despite the limited number of medical doctors joining psychiatry training programs. In examining the reasons as to why only limited numbers of medical doctors appeared to join psychiatry specialty as compared to other medical specialties in the country, first the authors of the study wanted to examine the attitude of medical students towards psychiatry. Thus, instead of rushing to examining the effect of psychiatry clinical attachment on attitudes of medical students towards psychiatry, because of lack of baseline data, the investigators assessed attitude towards psychiatry among fourth year medical students of Jimma University who completed psychiatry clinical rotation and those who did not take psychiatry clinical rotation in the academic year of 2012 .

\section{MATERIALS AND METHODS}

Study design: An institutional-based comparative cross-sectional study design was used to compare the attitudes of fourth year medical students who completed psychiatry clinical rotation and those who did not take psychiatry clinical rotation.

Study setting and period: The study was conducted in Jimma University from June $1^{\text {st }}$ to July $15^{\text {th }}$ in 2012 . Jimma University is located in Jimma Town which is $352 \mathrm{~km}$ far from Addis Ababa, the capital city of Ethiopia. The medical school at Jimma University (formerly Jimma Institute of Health Sciences) was launched in 1983. The university is one of the most reputable universities and centers of excellence in medical education in the country. Clinical psychiatry rotation for duration of six weeks for fourth year medical students has been part of the medical training.

Study participants: All the 122 fourth year medical students in the year 2012 were invited to participate in the study. Among them, 56 completed psychiatry clinical rotation while 66 did not yet take their psychiatry clinical rotation. During a six weeks' psychiatry course, medical students who completed psychiatry clinical

DOI: http://dx.doi.org/10.4314/ejhs.v27i3.2 
rotation were attending class room lectures, morning and ward round meeting sessions. Besides, they were involved in patient history taking and presenting it to their clinical supervisors (psychiatrists). Fourth year medical students who were repeating their psychiatry course, due to various reasons, were excluded from the study.

Measurement: The English version of the 30item self-administered Attitude towards Psychiatry (ATP-30) questionnaire was used to measure the attitude of medical students. The scale of ATP-30 was developed in Canada by Burra et al (1982) (27) and has a 5-ponit Likert type scale responses for the 30 items measuring the respondents' attitude to psychiatric patients, psychiatric illness, psychiatrists, psychiatry career choice, psychiatric treatment, psychiatric institutions and psychiatry teaching. This scale has been shown to have good psychometric properties among medical students (27). This scale previously was used in studies done in west and east African countries among medical students $(13,16)$. In this study, the ATP30 had three Likert scales (1=Disagree, $2=$ Neutral (no opinion), and $3=$ Agree) that generates a total score between 30 and 90 with a higher score indicating a positive attitude towards psychiatry. Prior to actual data collection, the investigators pre-tested the ATP-30 scale on $10 \%$ of the study participants among third and fifth year medical students of Jimma University. Accordingly, the reliability of the pre-tested ATP-30 was Cronbach's alpha of 0.80 .

Attitude refers to the feeling or approach of Jimma University fourth year medical students towards psychiatry as measured by the scale of ATP-30. Highest mean score on ATP-30 indicated favorable or positive attitude towards psychiatry and vice versa.

Medical students were fourth year students who were expected to take psychiatry clinical rotation as one course of their undergraduate medicine study in the academic year of 2012.

Psychiatry clinical rotation refers to Jimma University fourth year medical students' psychiatry clinical rotation/attachment at Jimma University Specialized Teaching Hospital, psychiatry ward in the year of 2012 .

Statistical analysis: Data was analyzed to generate descriptive statistics such as means, frequencies and percentages using statistical package for social sciences (SPSS version 20). Independent samples t-test was used to compare the difference in the mean ATP-30 scores of the study participants. Bivariate and multivariable logistic regression was used to identify factors independently associated with positive attitude towards psychiatry. P-value less than 0.05 was used to declare statistical significance. A total score was calculated by adding all the item scores. While scores above 60 were indicative of a favorable or positive attitude towards psychiatry, scores below 60 were used to show an unfavorable attitude; a score of 60 indicated a neutral attitude.

Ethical Approval: The ethical approval was obtained from the Research Ethical Review Board of the College of Public Health and Medical Sciences of Jimma University. An information sheet was attached with each questionnaire to provide the study details and the rights of the study participants. Written informed consent was obtained from the study participants. Data were kept anonymous and confidential during all stages of the study.

\section{RESULTS}

Background characteristics: Data were obtained from all 122 medical students who participated in the study. The age of the respondents ranged from 20 to 26 years with the mean age of 22.4 years and standard deviation of \pm 1.2 years. The majority of the students were male (78.7\%) and $82 \%$ and single. Of the total of the study participants, $14.8 \%, 25.4 \%$ and $32.8 \%$ reported personal history of mental illness, family or/close relatives history of mental illness and close friends history of mental illness respectively. More than half $(52.5 \%)$ of the students were originally from urban areas. Nearly $46 \%$ of the students had just completed psychiatry rotation (Table1). 
Table 1: Socio-demographic characteristics of the respondents

\begin{tabular}{llc}
\hline Variable & Categories & Frequency N (\%) \\
\hline Age & $20-22$ & $76(62.3)$ \\
& $23-26$ & $46(37.7)$ \\
Sex & Female & $26(21.3)$ \\
Marital status & Male & $96(78.7)$ \\
& In a relationship and Married & $22(18.0)$ \\
Place of origin & Single & $100(82.0)$ \\
Personal history of mental illness & Rural & $58(47.5)$ \\
& Urban & $64(52.5)$ \\
Family history of mental illness & Yes & $18(14.8)$ \\
& No & $104(85.2)$ \\
History of mental illness among close & Yes & $31(25.4)$ \\
friends & No & $91(74.6)$ \\
Psychiatry clinical rotation completed & No & $40(32.8)$ \\
& Yes & $82(67.2)$ \\
& No & $56(45.9)$ \\
& & $66(54.1)$ \\
\hline
\end{tabular}

Attitudes towards Psychiatry: The reliability of ATP-30 was Cronbach's alpha of 0.84 with mean 52.87, $\quad \mathrm{SD}=13.57, \quad$ minimum $=32.00$ and maximum $=88.00$. The mean ATP-30 score of medical students who did not take psychiatry clinical rotation was significantly higher than those who completed psychiatry clinical rotation with $\mathrm{p}=0.019$. Female students scored significantly higher mean on attitude towards psychiatry (ATP) compared to male students $(\mathrm{p}=$
0.002), which indicated medium effect size (i.e. Cohen's $d=0.71$ ); based on Cohen's (1988) criteria. The Participants with personal history of mental illness reported significantly higher mean of ATP compared to their counter parts ( $\mathrm{p}=$ $<0.001)$. Besides, participants with family history of mental illness scored significantly higher ATP mean compared to those participants without it $(\mathrm{p}=<0.001)$ (Table 2).

Table 2: ATP-30 mean scores of the study participants

\begin{tabular}{lllll}
\hline Variable & Category & $\begin{array}{l}\text { Mean } \pm \text { SD of ATP- } \\
\mathbf{3 0}\end{array}$ & t (df) & P-value \\
\hline Sex & Female & $60.19 \pm 15.49$ & $3.22(120)$ & 0.002 \\
& Male & $50.57 \pm 12.18$ & & \\
Personal history of mental & Yes & $66.56 \pm 14.71$ & $-5.09(120)$ & 0.000 \\
illness & No & $50.50 \pm 11.92$ & & \\
Family history of mental illness & Yes & $60.29 \pm 15.71$ & $-3.71(120)$ & 0.000 \\
& No & $50.34 \pm 11.82$ & & \\
Close friends history of mental & Yes & $50.73 \pm 13.11$ & $1.22(120)$ & 0.22 \\
illness & No & $53.92 \pm 13.64$ & & \\
Psychiatry clinical rotation & Yes & $49.75 \pm 10.67$ & $2.38(120)$ & 0.019 \\
completed & No & $55.52 \pm 15.19$ & & \\
\hline ATP=Attitude & & & &
\end{tabular}

ATP=Attitude towards Psychiatry

DOI: http://dx.doi.org/10.4314/ejhs.v27i3.2 
Factors associated with Positive attitude towards psychiatry: Female medical students were nine times more likely to have positive attitude towards psychiatry than male students $(\mathrm{OR}=9.23, \quad 95 \%$ CI: 2.32; 36.76). Younger medical students had a marginally positive attitude than older ones $(\mathrm{OR}=3.86,95 \% \mathrm{CI}: 1.00 ; 14.90)$. Students who did not take their psychiatry clinical rotation were 7.6 times more likely to have positive attitude towards psychiatry than those who had completed psychiatry clinical rotation (OR=7.58, 95\% CI: 2.02; 28.37) (Table 3). On the other hand, medical students with personal history of mental illness had 14.5 times more positive attitude towards psychiatry than those medical students without it $(\mathrm{OR}=14.53, \quad 95 \%$ CI:3.08;68.59). Similarly, students with family history of mental illness were 8.9 times more likely to have positive attitude towards psychiatry than those who had no family history of mental illness (OR=8.95, 95\% CI: 2.50; 32.00). However, variables such as marital status, place of origin and close friends' history of mental illness of the study participants did not significantly account for their difference on attitude towards psychiatry $(\mathrm{P}>0.05)$ (Table 3).

Table 3: Logistic regression analysis results on factors predicting attitudes towards psychiatry

\begin{tabular}{|c|c|c|c|c|c|}
\hline \multicolumn{2}{|c|}{ Variables } & \multirow{2}{*}{$\begin{array}{c}\text { Positive ATP } \\
30.9 \%\end{array}$} & \multirow{2}{*}{\begin{tabular}{|c|} 
COR $(95 \%$ CI $)$ \\
$2.89(1.078-7.77)$
\end{tabular}} & \multirow{3}{*}{$\begin{array}{l}\begin{array}{l}\text { Adjusted OR } \\
(95 \% \text { CI })\end{array} \\
3.86(1.00-14.90)\end{array}$} & \multirow{2}{*}{$\begin{array}{l}\text { P-value } \\
0.050\end{array}$} \\
\hline Age & $20-22$ & & & & \\
\hline & $23-26$ & $13.0 \%$ & 1.00 & & \\
\hline \multirow[t]{2}{*}{ Sex } & Female & $50.0 \%$ & $5.00(1.96-12.77)$ & $9.23(2.32-36.76)$ & 0.002 \\
\hline & Male & $16.7 \%$ & 1.00 & & \\
\hline \multirow[t]{2}{*}{ Marital status } & $\begin{array}{l}\text { In relationship } \\
\text { and married }\end{array}$ & $31.8 \%$ & $1.66(0.60-4.56)$ & & \\
\hline & Single & $22.0 \%$ & 1.00 & & \\
\hline \multirow[t]{2}{*}{ Place of origin } & Rural & $27.6 \%$ & $1.50(0.65-3.46)$ & & \\
\hline & Urban & $20.3 \%$ & 1.00 & & \\
\hline \multirow{2}{*}{$\begin{array}{l}\text { Personal history } \\
\text { of mental illness }\end{array}$} & Yes & $72.0 \%$ & $14.30(4.48-45.65)$ & $14.53(3.08-68.59)$ & 0.001 \\
\hline & No & $15.4 \%$ & 1.00 & & \\
\hline \multirow{2}{*}{$\begin{array}{l}\text { Family history of } \\
\text { mental illness }\end{array}$} & Yes & $48.4 \%$ & $5.16(2.08-12.76)$ & $8.95(2.50-32.00)$ & 0.001 \\
\hline & No & $15.4 \%$ & 1.00 & & \\
\hline \multirow{2}{*}{$\begin{array}{l}\text { Close friends } \\
\text { history of mental } \\
\text { illness }\end{array}$} & Yes & $15.0 \%$ & 1.00 & & \\
\hline & No & $28.0 \%$ & $2.21(0.82-5.96)$ & & \\
\hline \multirow{2}{*}{$\begin{array}{l}\text { Psychiatry clinical } \\
\text { rotation completed }\end{array}$} & Yes & $10.7 \%$ & 1.00 & & \\
\hline & No & $34.8 \%$ & $4.46(1.66-11.96)$ & $7.58(2.02-28.37)$ & 0.003 \\
\hline
\end{tabular}

Constant $=-5.24$, Wald $=26.18$, Reference $=1.00, \mathrm{ATP}=$ Attitude

\section{DISCUSSION}

Medical students who did not yet do psychiatry clinical rotation during their medical studies were more likely to have a more favorable attitude towards psychiatry than students who had just completed their psychiatry clinical rotation. Furthermore, female medical students and medical students with a personal or family history of mental illness were more likely to have a favorable attitude towards psychiatry. Younger medical students were also likely to have a favorable attitude towards psychiatry although this could have been due to chance.

A few other studies have also reported negative attitude towards psychiatry among students following psychiatry training $(22,23)$. However, several studies from western, African, and Middle East countries have found that medical students had positive attitude to psychiatry following clinical posting in the field (9-18). Our 
finding suggests that the psychiatry clinical rotation might have resulted in a more negative attitude towards psychiatry among the medical students. Nevertheless, the findings could have been due to disparity between medical students' expectations of the clinical psychiatry and the actual practice. The other possible reason could be that the students' ratio to very limited number of psychiatrists might have led medical students not to have adequate supervision time during their exposure to mentally ill patients. Further research thus is needed to confirm this. In particular, a qualitative study of the medical students' experience during their psychiatry clinical rotation will be useful to interpret the findings.

On the other hand, in this study, female medical students had significantly positive attitude towards psychiatry than male ones, which is supported by a previous research done in Pakistan (21) but contradicted with the study report done in UK (12) which found that both male and female students did not differ in their attitudes towards psychiatry. This could imply that female medical students from developing countries have more favorable attitude towards psychiatry than males.

The finding that medical students with family history of mental illness were found to have positive attitude towards psychiatry is supported by a previous study (11). Besides, participants with personal history of mental illness reported significantly positive attitudes toward psychiatry. Perhaps, medical students who had personal experience of mental illness were likely to empathize with other patients with mental illness and were able to witness the beneficial effect of psychiatric interventions. A period of five or six weeks of clinical rotation in a psychiatry clinic where there are frequent shortage of essential psychotropic medications and lack of rehabilitation services (28) does not offer the opportunity for trainees to witness recovery of patients with mental illness.

On the other hand, this study found that young medical students had more favorable attitudes towards psychiatry than older ones; which is similar with results of previous studies (17). This may indicate that as the age of medical students increases, attitude towards psychiatry became marginally negative which might be a chance finding. Perhaps, a larger sample of students from several representative medical schools will help understand if a true relationship exists between age and attitude towards psychiatry. The absence of association between marital status and medical students' attitude towards psychiatry was reported in another study (3).

As psychiatry clinical rotation during medical school training provides a rare opportunity to create a positive attitude among young doctors, psychiatrists involved in teaching need to address the issue. Negative attitude towards the field of psychiatry means that there will be fewer young doctors who wish to pursue their career in psychiatry. It is thus a barrier to building mental health manpower in this field of specialty in the country.

The study suffers the following limitations. Firstly, the participants were selected from one medical school, and the findings may not be generalizable to all medical schools in Ethiopia. As the study is cross-sectional in design, causal association cannot be established based on the findings. The relatively small sample size might have led to under-power. Also, social desirability bias might have influenced the response of the participants although it is less likely as the questionnaire was self-administered.

Despite the limitations, the findings shed light on the attitudes towards psychiatry of medical students in Ethiopia. The observation that completing psychiatry clinical rotation is associated with less favorable attitude towards psychiatry is alarming and requires further investigation into the pedagogic aspects of psychiatry training. Longitudinal studies with mixed methods approach will help understand if the current psychiatry teaching in the medical school influences the medical students' attitude towards psychiatry.

\section{ACKNOWLEDGMENT}

The investigators of this study pass their deepest thank to Jimma University for supporting the research activities financially.

DOI: http://dx.doi.org/10.4314/ejhs.v27i3.2 


\section{AUTHORS' CONTRIBUTIONS}

Except the 4th author, the remaining authors of this article had equal contribution in generating the study ideas (such as title selection, objective stating and research methodology determination) during research proposal development. Besides, they actively involved in analyzing the collected data and providing useful comments for this manuscript preparation. However, the 4th author mainly contributed to the analysis and interpretation components of the study. Furthermore, this author has actively worked in manuscript preparation.

\section{REFERENCES}

1. Kessler R, Aguilar-gaxiola S, Alonso J, Chatterji S, Lee S, Ormel J, et al. The global burden of mental disorders: An update from the WHO World Mental Health (WMH) Surveys. Epidemiol Psichiatr Soc2009; 18(1):23-33.

2. WHO. Reducing Risks, Promoting Healthy Life. World Health Organization: Geneva 2002.

3. WHO. Investing in mental health. Geneva2003.

4. Kohn R, Saxena S, Levav I, Saraceno B. The treatment gap in mental health care. Bulletin of the World Health Organization 2004; 82(03):858-66.

5. Patel V. The future of psychiatry in low- and middle-income countries. Psychological Medicine 2009; 39:1759-62.

6. WHO. Human resources for mental health: workforce shortages in low- and middleincome. Geneva. 2011(8).

7. Weintraub $\mathrm{W}$, Plaut $\mathrm{S}$, Weintraub E. Recruitment Into Psychiatry: Increasing the Pool of Applicants. Can J Psychiatry; 44:4737.

8. WHO. WHO-AIM Report on Mental Health Systems in Ethiopia. Addis Ababa, Ethiopia: World Health Organization, Ministry of Health Ethiopia 2006.
9. Samimi M, Noroozi R, Mottaghipour Y. The Effect of Psychiatric Clerkship on Fifth Year Medical Students' Attitudes toward Psychiatry and Their Intention to Pursue Psychiatry as a Career. Iran J Psychiatry2006; 1:98-103.

10. McParland M, Noble L, Livingston G, McManus C. The effect of a psychiatric attachment on students' attitudes to and intention to pursue psychiatry as a career. Medical Education2003; 37:447-54.

11. Guillem Pailhez G, Bulbena A, Joaquim Coll J, Ros S, Balon R. Attitudes and Views on Psychiatry: A Comparison Between Spanish and U.S. Medical Students. Academic Psychiatry2005; 29:82-91.

12. Singh S, Baxter H, Standen P, Duggan C. cahnging the attitudes of 'tomorrow doctors' towards mental illness and psychiatry: a comparison of two teaching methods. Medical education1998; 32:115-1250.

13. Manassis K, Katz M, Lofchy J, Wiesenthal S. Choosing a Career in Psychiatry: Influential FactorsWithin a Medical School Program. Academic Psychiatry2006; 30:325-9.

14. Garyfallos G, Adamopoulou A, Lavrentiadis G, Giouzepas J, Parashos A, Dimitriou E. Medical Students' Attitudes Toward Psychiatry in Greece. Academic Psychiatry1998; 22:92-7.

15. J XMaA. Impact of clerkship in the attitude toward psychiatry among Portuguese medical students. BMC medical education2010; 10:56.

16. Reddy J, Tan S, Azmi M, Shaharom M, Rosdinom R, Maniam T, et al. The Effect of a Clinical Posting in Psychiatry on the Attitude of Medical Students towards Psychiatry and Mental Illness in a Malaysian Medical School. Ann Acad Med Singapore2005; 34:505-10.

17. Aslam M, Taj T, Ali A, Badar N, Saeed F, Abbas M, Muzaffar S, Abid B. Psychiatry as a career: A survey of factors affecting students' interest in Psychiatryas a career. MJM 2009; 12(1):7-12.

18. Galka S, Perkins D, Butler N, Griffith D, Schmetzer A, Avirrappattu G, Lafuze J. Medical Students' Attitudes Toward Mental Disorders Before and After a Psychiatric 
Rotation. Academic Psychiatry2005; 29:35761.

19. Ndetei D, Khasakhala L, Ongecha-Owuor F, Kuria M, Mutiso V, Syanda J, Kokonya D. Attitudes Toward Psychiatry: A Survey of Medical Students at the University of Nairobi, Kenya. Academic Psychiatry2008; 32:154-9.

20. Laugharne R, Appiah-Poku J, Laugharne J, Shankar R. Attitudes Toward Psychiatry Among Final-Year Medical Students in Kumasi, Ghana. Academic Psychiatry2009; 33:71-5.

21. Ali Khan S, Yousafzai A, Kausar Mehir R, Inam-ul-Haq. Attitude of medical students towards psychiatry in NWFP. J Ayub Med Coll Abbottabad2008; 20(3).

22. Issa B, Adegunloye $\mathrm{O}$, Yussuf $\mathrm{A}$, Oyewole $\mathrm{O}$, Fatoye F. Attitudes of Medical Students to Psychiatry at a Nigerian Medical School. Hong Kong J Psychiatry2009; 19:72-7.

23. Ahmed A, Ala'a A. Attitude of Arabian Gulf University Medical Students towards Psychiatry. Education for Health 2002;15(2):180-8.

24. Fischel T, Manna H, Krivoy A, Lewis M, Weizman A. Does a Clerkship in Psychiatry
Contribute to Changing Medical Students' Attitudes Towards Psychiatry? Academic Psychiatry2008; 32:147-50.

25. Kuhnigk S, Schilauske, Jueptner J. Attitudes of medical students towards psychiatry : effects of training, courses in psychiatry, psychiatric experience and gender. Advances in health sciences education: theory and practice2007 Feb; 12(1):87-101.

26. Tharyan P, John T,Tharyan A, Braganza D. Attitudes of 'tomorrow's doctors' towards psychiatry and mental illness. The national medical journal of India2001; 14(6):355-9.

27. Burra P, Kalin R, Leichner P, Waldron J, Handforth J, Jarrett F, et al. The ATP 30- a scale for measuring medical students' attitudes to psychiatry. Medical Education 1982 2015/09/25/19:00:10; 16(1):31-8.

28. Addisu F, Wondafrash M, Chemali Z, Dejene $\mathrm{T}$, Tesfaye $\mathrm{M}$. Length of stay of psychiatric admissions in a general hospital in Ethiopia: a retrospective study. International Journal of Mental Health Systems2015;9:13. 